\title{
Information and Health Literacy in the Balance: Findings from a Study Exploring the Use of ICTs in Weight Management
}

\author{
Audrey Marshall, Flis Henwood, and Elizabeth S. Guy
}

\begin{abstract}
This article uses findings from a UK Department of Health funded research study known as Net.Weight to reflect on the concept of information literacy as it relates to consumer health. It explores how the results support and develop an understanding of information and health literacy and it offers recommendations for policy and practice. The study was located in the city of Brighton \& Hove and examined the potential for information and communication technologies (ICTs) to support people who were self-managing their weight. The research comprised five interlocking components, at the heart of which was a series of participatory learning workshops designed to develop participant skills in relation to ICTs, information, and health literacy. The results indicate that a broader and more social understanding of information literacy is needed to ensure a better "fit" between the provision and use of health information. They also indicate that ICTs can augment information provision and support activities, but that a "blended" approach is necessary, where online and 'real world' communication work in tandem.
\end{abstract}

\section{INTRODUCTION}

Information has been a key strand of UK government policy on health care since the 1990s but the emphasis has tended to be on information provision rather than use, with little attention paid to the health literacy skills of end users. This article draws on a study that explored the potential for information and communication technologies (ICTs) to support people who were self-managing their weight ${ }^{1}$ to explore information and health literacy from a user perspective and to examine the implications of these findings for policy and practice. The article engages with compet- 
ing theoretical and conceptual understandings of information and health literacy to develop a critique of current policy and practice and builds on findings from the Net.Weight study to support the argument for a broader social model of information literacy in the context of health.

\section{Health Information Policy}

Information came into the health policy foreground in the United Kingdom as part of a modernization agenda for the National Health Service (NHS) in 1998, with the publication of Information for Health (NHS Executive, 1998). Since then, information has been understood as a central resource for the organization and delivery of health care in the United Kingdom, with Information and Communication Technologies (ICTs) seen as having a crucial role. The NHS Constitution (Department of Health, 2010a) makes information provision a legal obligation and initiatives such as Information Prescriptions (Department of Health, 2009) highlight the importance of information in long-term care. There have also been key national initiatives around providing information on the Internet, including NHS Direct Online (NHS Direct, 1999) and more recently NHS Choices (Department of Health, 2008). A recent UK government consultation document Liberating the NHS: An Information Revolution (Department of Health, 2010b) sets out a vision for an "information revolution" where "people have the information they need to stay healthy ..." (p. 5). However, despite the perceived importance of information as a vehicle for delivering effective health care, there has been little emphasis in the UK on how people find, evaluate, and use information for health; in other words on the health literacy skills of end users. In its response to the 2010 consultation, the consumer health umbrella group National Voices highlights this lack of focus, arguing that the consultation "does not adequately address the need for patients and service users to receive help, advice and support to become skilled and confident at using information for decisions about their health, care and treatment" (National Voices, 2010, p. 18). This is not a new criticism of UK government policy. Coulter and Ellins (2006), in a review of patient-focused interventions, argue that public debate and policy in the UK have been consistently more focused on the provision of health information than on health literacy and that there is a need for more research into the levels and effects of low health literacy levels.

\section{Health Literacy}

Conceptually, the Net.Weight study sits at the intersection of different literacies, notably information, digital, and health literacy, in an area that has been defined by Norman and Skinner (2006) as e-health literacy. They argue that being health literate in an electronic world requires an expanded set of skills, incorporating six core skills or literacies: traditional 
literacy, health literacy, information literacy, scientific literacy, media literacy, and computer literacy. Health literacy, as a concept related to information literacy, has been explored more thoroughly by library and information professionals in the United States (Kars, Baker, \& Wilson, 2008) than in the United Kingdom, although this situation is changing. Smith and Duman (2009), for example, in an article that presents an overview of consumer health information in the United Kingdom, argue that understanding and improving health literacy are key objectives for anyone working in consumer health information.

Information literacy has been variously defined (see CILIP, 2007; SCONUL, 1999). Most definitions imply a cycle of activity, comprising distinct and separate stages, typically: information need recognition, search formulation, source selection and interrogation, information evaluation, and information synthesis and use. This information literacy cycle has also been used in health contexts. Craig (2009), for example, describes how the cycle was used as a process model for a training initiative for the NHS in Scotland, which aimed to develop information skills in health and social care professionals, as well as patients and carers.

Nutbeam (2008) takes health rather than information as the context for conceptualizing health literacy and he traces the development of two distinctly different approaches to health literacy, arising out of on the one hand, clinical, and on the other hand, public health disciplines. He argues that the clinical approach emphasizes an individual's capacity to understand basic health information and service provision, while the public health approach focuses more on a set of skills that enable people to participate in their own health and well-being: "Health literacy represents the cognitive and social skills which determine the motivation and ability of individuals to gain access to, understand and use information in ways which promote and maintain good health" (World Health Organization, 1998). This broader definition is notable for its incorporation of social, as well as cognitive skills and it provided a useful framework for the participative aspects of Net.Weight, which were a key part of the study design. The definition's inclusion of the concept of motivation was also useful, in that motivation, often arising out of mutual support, is a key factor in weight management and was identified as such by Net.Weight participants.

\section{The Net.Weight Study}

The Net.Weight study, formally entitled "Supporting the Self Management of Obesity: The Role of Information and Communication Technologies," was funded by the Department of Health in the United Kingdom, under their Policy Research Programme: "Technologies to Support Self Care, Chronic Disease Management and Healthy Living." It examined the potential for increased, innovative, and effective uses of information and communication technologies (ICTs) to support people who are 
self-managing weight. It was located in the city of Brighton \& Hove, on the south coast of England, and conducted by a multidisciplinary team from the University of Brighton and Brighton and Sussex Medical School. The research team worked in partnership with a number of local organizations in the statutory, community, and voluntary sectors. Project participants were all either overweight or obese (using BMI measures) and "trying to do something about it," in other words already actively engaged in some form of self-care.

The research had five key objectives:

- To map the "information landscapes" of those involved in the self-management of obesity from provider and user viewpoints

- To identify the opportunities and challenges posed by ICTs in the selfmanagement of obesity

- To identify the specific IT, information and health literacy skills and needs of those seeking to make use of ICTs in this context

- To design and run a series of participatory learning workshops to address skills needs and identify ways to better organize local health information to support obesity self-management

- To evaluate the impact of participation in these workshops in terms of its ability to lead to increased, innovative and effective uses of ICTs to support the self-management of obesity in one locality

The study had several interrelated research strands as illustrated in figure 1 and comprised five key stages.

- Provider mapping. This stage identified key providers of information, advice, and support for healthy living across the city. The data was presented on a Web-based, searchable directory and made available via the Net.Weight Community website (Netweight Study, 2008). It supported the participatory learning workshops, which formed stage four, and at which the local resources were evaluated by the participants.

- User mapping. This strand produced a detailed picture of users' "information landscapes" using a questionnaire-based survey and four community-based focus groups. For the survey, paper-based self-completion questionnaires were made available at strategic locations throughout the city, including GP practices, pharmacies, and community centers. An online version of the questionnaire was also made available via some of the city's major employers. Data were collected on respondents' current health status, their weight management goals and practices, their sources and needs with respect to information, advice, and support for weight management and their use of the Internet and other ICTs. A total of 454 questionnaires were returned, of which 385 were valid and used for analysis. 


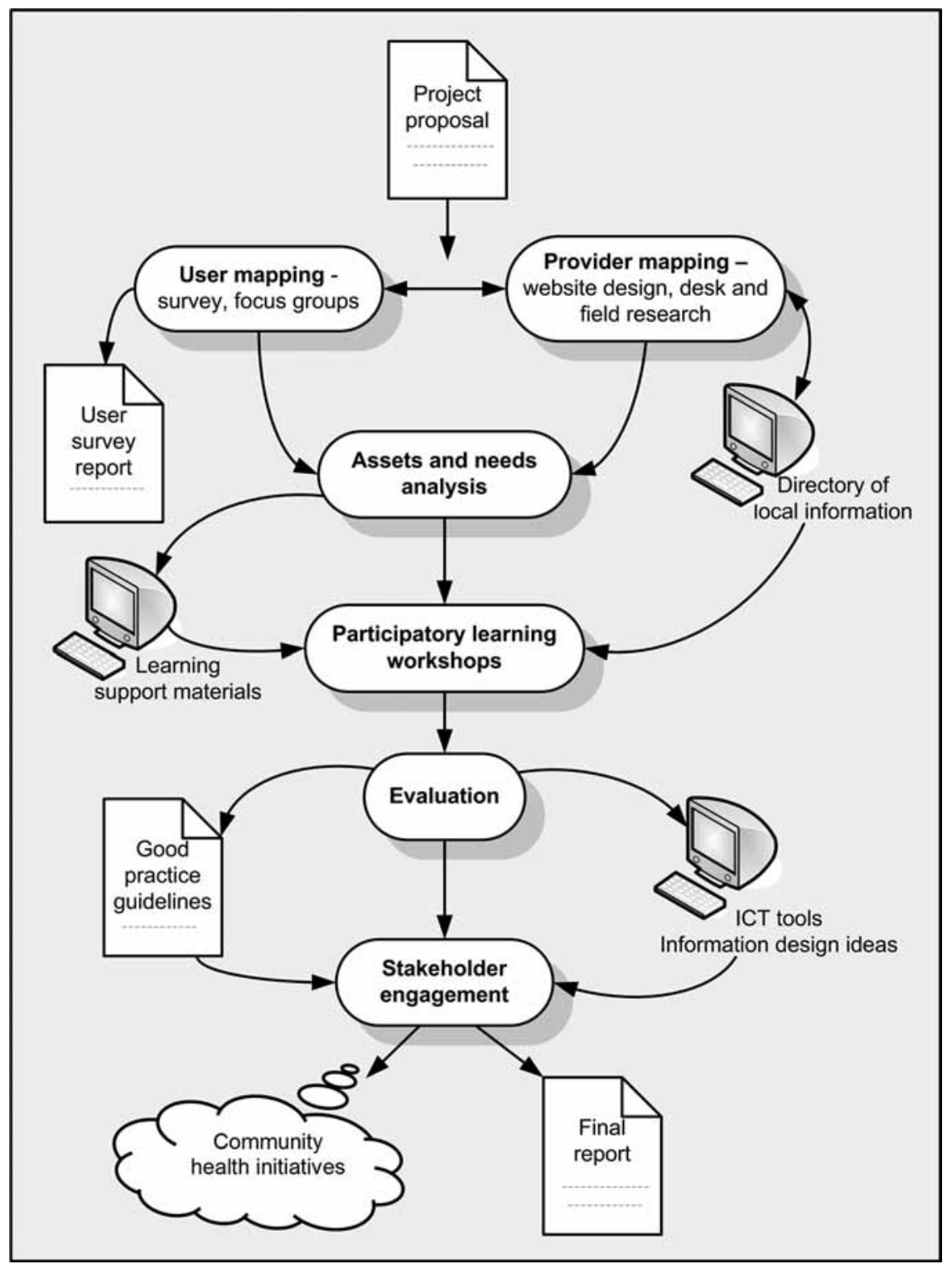

Figure 1 
- Assets and needs analysis. The analysis drew on the user mapping data to identify the existing skills, knowledge, and needs of respondents in relation to health, information, and IT use in the context of weight management. The Statistical Package for the Social Sciences (SPSS) and NVivo were used to support the analysis of the survey and focus group data. The findings fed directly into the design of the participatory learning workshops that formed the next stage of the study and into developing a set of learning support materials for use in the workshops.

- Participatory learning workshops. The workshops were at the heart of the project. They were designed and run to support and develop confidence, competence, and critical skills in the relation to ICT, information, and health literacy in the context of weight management. Three sets of four workshops were run, with a total of thirty-nine participants attending at least one workshop. The participants included thirtyone women and eight men and had an average age of fifty-seven. The participants were recruited through two main routes: the user survey, where respondents were given an opportunity to register their interest at the end of the questionnaire; and community engagement events, organized with the project partner organizations. The content and timing of the workshops was defined as much as possible by user needs, according to the principles of participatory design, and they covered four key areas: information sources and skills (Information Guided Tour); social networking (Sharing and Community); writing and blogging (In Our Own Words); and redesigning an existing website (Making the future). Before the workshops began, participants were encouraged to complete a short questionnaire to assess their own perceived level of skill and experience related to ICT, information, and health literacy. As well as contributing to the workshop design this data also assisted with the reflection on change undertaken in the post-workshop interviews. Thirty-two of the thirty-nine participants completed the preworkshop questionnaire.

- Evaluation. Evaluation was conducted both on an ongoing basis and at the end of the study. Data was captured on participants' experiences of the workshops as they progressed and was used to feed back into the design process. Interviews were held with participants six months after the workshops to measure the success of workshops in terms of increasing participants' ability to engage effectively and critically with health information and ICTs in support of their self-defined health goals. Eighteen of the thirty-nine workshop participants were interviewed toward the end of the project, sixteen of whom had completed the preworkshop questionnaire. Of the eighteen interview participants, fourteen were women and four were men; sixteen of the eighteen interviewees were over fifty. 


\section{Results}

The final report of the study was submitted to the Department of Health at the end of the project (Henwood, Marshall, Carlin, Guy, \& Smith, 2009). This article discusses the results through two different but related perspectives. Firstly, it explores how the results support and develop an understanding of information and health literacy. Secondly, it offers suggestions as to how the key findings might be put into practice by organizations responsible for providing health information.

\section{Information Sources}

As noted above, most models of information literacy incorporate a cycle of staged activity - typically information need recognition, search formulation, source selection and interrogation, information evaluation, and information synthesis and use. In order to identify the types of information used by people involved in weight management, the Net.Weight survey asked respondents to indicate the sources of information they had found to be useful from a list of fifteen options. The list was derived from instruments used by MORI (Department of Health, 2005), the Picker Institute (Ellins \& Coulter, 2005), and Huntington, Nicholas, Williams, \& Gunter (2002). Figure 2 shows the perceived usefulness of the different information sources.

As can be seen from figure 2, the sources that had the highest rating for "always useful" in the Net.Weight study were slimming groups (34.7 percent) and food packaging (23.7 percent). Aggregating "always useful" and "sometimes useful," food packaging, friends and family, and magazines were rated most highly. Thus, the most useful sources of information for this group of people are informal rather than formal; and encountered rather than sought out. This presents a challenge to the view of information literacy as a model with staged activity. It can be argued that there is indeed a fit between-on the one hand-recognizing an information need, formulating a search strategy, selecting and interrogating a source and-on the other hand-examining the packaging on food during the weekly shop. However, it is more difficult to see such a neat fit when the information source is slimming groups, friends and family, or magazines. Indeed, the process in which people such as the Net.Weight survey respondents are engaged is much more complex than the staged model suggests and more akin to the information strategies described by Kuhlthau (2008) and McKenzie (2003). Kuhlthau argues that people with everyday life information needs, including health-related needs, construct their information from a variety of sources over an extended period of time. She cites Bates' berry picking metaphor (Bates, cited in Kuhlthau 2008, p. 67) to illustrate that people move from one source to another and extract only certain items for use. McKenzie (2003) demonstrated similarly that, in everyday situations, people move fluidly from one type of information seeking 


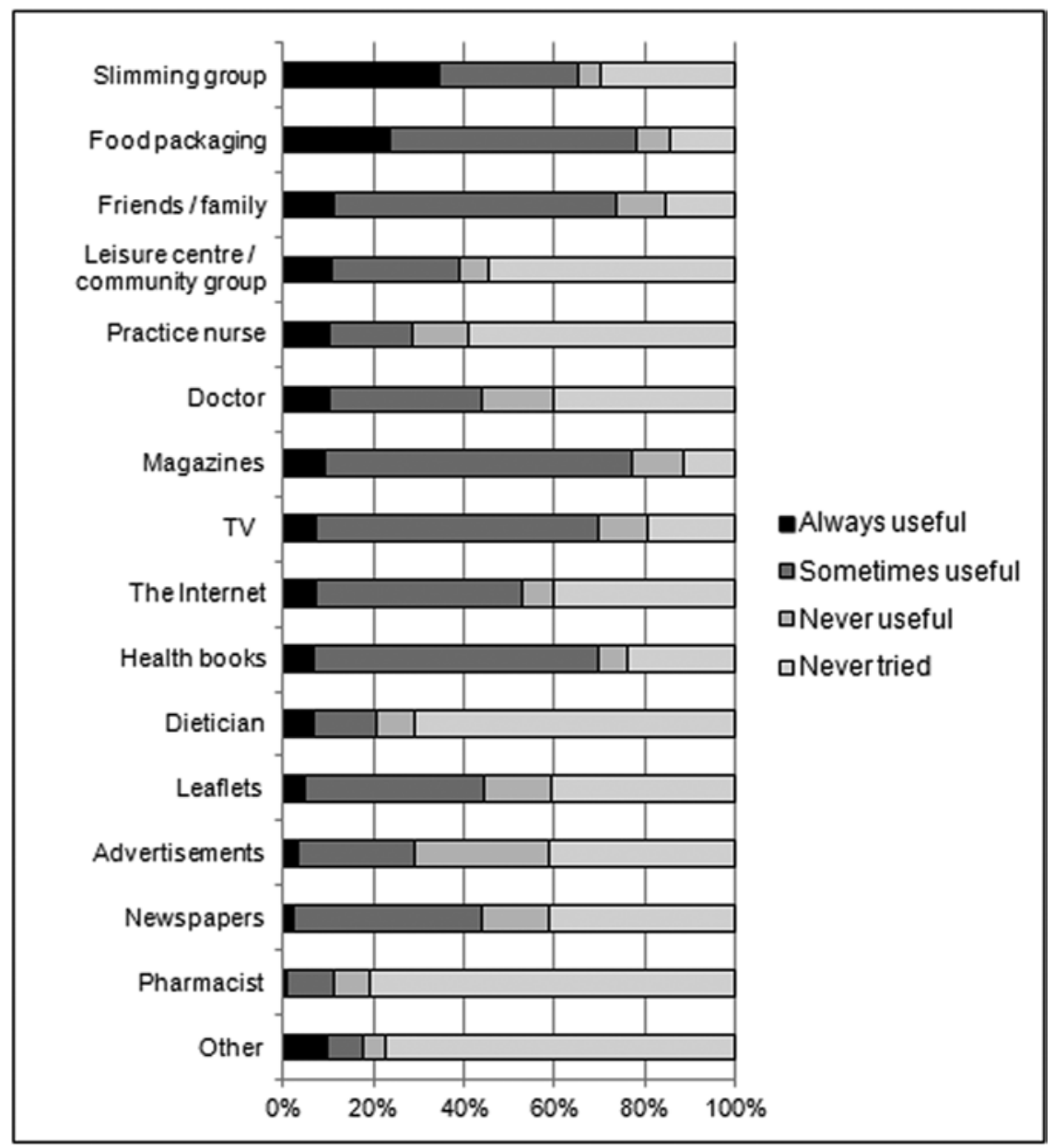

Figure 2

behavior to another, for example, from contacting a doctor to looking something up in a book to engaging in conversation with another person in a similar situation. Thus, the first stages of the information literacy cycle need to be expanded or adapted to reflect this more complex interaction with information.

Moving round the information literacy cycle to information evaluation, this topic was addressed explicitly in the workshops. Part of the aim of the first workshop in the series, Information Guided Tour, was to explore information quality assessment in the context of weight management. The participants had the opportunity to explore online quality 
assessment tools for themselves and to apply the principles of assessment to the information they were finding online. The findings showed that while people understood what the assessment tools were attempting to do they were more likely to look for a "fit" with their own tacit knowledge or personal experience. One workshop participant commented of the tools that they are what an intelligent person would think anyway and another said that one's critical faculties "come naturally." A third said: "It's more a matter of if a site feels right for you then you use it." In the post-workshop interviews, participants reiterated this theme: "You look at [a website] and think well this is a load of rubbish" [Interviewee]. The study supports the assertion from Adams, de Bont, and Berg (2006) that people do not "have a standard list of points" when they assess information. As one interviewee said: "I'm not sure I actively look at things in that way" [Interviewee]. Adams, de Bont, and Berg (2006, p. 71) go on to suggest that instead of a list of points people "pragmatically juxtapose different signs in order to build their judgment," a contention that again is supported by some of the Net. Weight comments: "I can't judge it to the degree whether it's good information or bad information; I can only make a decision on if that information suits me" [Interviewee]. Net.Weight therefore suggests that people do engage in evaluation processes, but in a way that is again more complex than the staged approach implied in the information literacy models.

The final stages of the typical information literacy cycle represent information synthesis and use. The Net.Weight participants were largely knowledgeable about weight-related issues but they lacked information that was specific to their personal situation, often complex and often related to other health problems. One survey respondent, for example, wanted information about exercise for osteoarthritis and a workshop participant wanted information on losing weight gained as a result of cancer treatment. While policy tends to emphasize "getting the right information to the right people at the right time," Net.Weight participants did not experience information provision this way and the "personalisation" of information remains an important challenge for information providers, who are exploring the potential of Web 2.0 type technologies in this regard.

Perhaps even more significant than the need for "personalised" or "tailored" information, was the finding that information plays a less significant role in weight management than policy discourse would suggest. When commenting on their strategies for coping with the complex and intractable problem of weight management, Net.Weight participants downplayed the significance of "information" in favor of "support." Comments from participants included: "Information? Sure, but losing weight is hard work!!!!!!!!!!!!!!!!!!”; "Information is not the problem, will power is!"; "I already feel confident about finding information but I fail to use the information correctly"; "I'm confident enough about this-it's putting all the information and my knowledge into practice, that's the crunch" "I think I 
know what I need to do. . . so maybe some source of support." The Net. Weight findings suggest that some groups of people, such as those engaged in managing their weight over the long term, need support as much as information, although responses suggest that the two are closely linked. This helps to explain the usefulness of slimming groups and friends and family as sources of "information." The limitation of information is well recognized in public health: "Merely providing information does not in itself ensure that it is used. This is a well-known phenomenon in public health, where people may be aware of health promotion messages but do not change unhealthy behaviours" (National Voices, 2010, p. 18). However, this limitation has been downplayed in the consumer health information literature, where the focus over the last two decades has been on health information quality and quality assessment (Marshall \& Williams, 2006; Shepperd, Charnock, \& Gann, 1999). More recently Smith and Duman (2009) acknowledge that "information on its own can achieve very little" and that "human contact" and "communication" are essential. The results from Net.Weight add to this evidence and raise further questions with regard to the information literacy staged model. An extra dimension is needed at the synthesis and use stages, to reflect the fact that information in itself is not always sufficient and that, certainly where health behaviors are concerned, other interventions are often needed.

\section{Social Action}

The need for support expressed or implied by the Net.Weight participants resonates with the reasons they gave for joining the workshops, which were: to share their experience, to learn from other people with similar problems, and to participate in a support network. Indeed, the workshops became a setting for mutual support and the informal exchange of information. This happened alongside the more formal or structured aspects of the workshop activities, particularly during practical hands-on and discussion sessions, when participants increasingly shared information about a wide range of subjects including local restaurants, favorite recipes, leisure activities, and advice along "what worked for me" lines. In their evaluative interviews participants spoke positively about this information sharing aspect of the workshops, as illustrated in the following reflection: "I think collectively we had a lot of information and I think that was good. That was probably as big a part of it and as useful a part of it as any other. In that just people's ... experiences are always really useful and interesting, aren't they?" [Interviewee].

The consumer health information literature, particularly through its focus on health information quality and quality assessment (Cullen, 2005; Marshall \& Williams, 2006), tends to imply a distinction between providers and users of information. Smith and Duman (2009) also make this distinction, which largely ignores the fact that people can be both. The 
interaction between users and within communities and the way in which this interaction itself generates information is largely ignored in the literature. An exception to this is Childs (2004) who makes the point that in the context of sick children, support group workers are often themselves parents of such children and that both groups are equally knowledgeable about issues relating to their health conditions, with similar information needs and information-producing potential. Evidence from the Net.Weight study supports an approach to information provision that acknowledges the contribution that "lay" experts can make.

The Net.Weight study concluded that people who are attempting to manage their weight, find and use information in ways that are more complex than the staged approach to information literacy would suggest. As Webber and Johnston (2000) argue, there is a danger in the "tick box" approach to information literacy, "reducing a complex set of skills and knowledge to small, discrete units" (p. 384). In a later article, they reconceptualize information literacy as a "soft applied discipline rather than ... a set of personal attributes" (Johnston \& Webber, 2006, p. 109), which echoes Nutbeam's (2008) argument about the need to see health literacy as an asset that enables engagement in social action. Much has been made in information science of the user-information interaction but results from the Net.Weight study suggest the need to incorporate a further dimension into this equation, that of user-user-information (Marshall, Henwood, Carlin, Guy, \& Smith, 2010). Such an approach would help increase understanding of the complex processes that constitute people's real-life information practices and ensure a better "fit" between the provision and use of health information.

\section{Policy and Organization Lessons}

Since the Net.Weight project ended in 2009, there has been a change of government in the United Kingdom, and the coalition government has proposed sweeping changes to the way in which the NHS is governed (Department of Health, 2010c). Responsibility for local health improvement, for example, will become the remit of local government rather than the NHS. However, the key lessons of Net.Weight remain valid and the practical implications of the study, particularly with regard to local information providers, are now examined.

\section{Tailored Information}

As has been discussed above, most people who are actively involved in weight management have no further need for generic information about healthy living, which they experience as being "pushed" at them. What they do need is more specific information, which addresses personal circumstances and goals. They want to find information about health, weight, and exercise that relates to their age, state of health, mobility problems, 
and special dietary requirements. At policy level, there are worrying signs that this lesson has not been learned. Criticism levelled at Liberating the NHS points out that "the description of the information revolution neglects the needs for patients and service users to receive tailored and timely information ..." (Patient Information Forum, 2011, p. 5).

At organizational level, there is potential for much wider use of Web 2.0 technologies in tailoring information. NHS Choices (Department of Health, 2008) provides a benchmark for the imaginative use of innovative technologies. In the Healthy Eating area, for example, there are tools to enable people to measure their BMI, assess their fitness levels, use a supermarket health checker to help cut the fat, salt, and sugar in a weekly shopping trip and find a local weight support group. However, although it points the way, even these tools are not sufficiently specific in the way that the Net.Weight participants wanted and needed. In fact, the Net.Weight participants remained largely unimpressed by NHS Choices when they explored it in the Information Guided Tour workshop. This may have been due to technical access problems, particularly in one of the venues, as some participants commented that they found the site rather slow and that they could not access parts of it. However, despite the muted response in the workshops, the research concluded that there is a need to make more use of the potential for personalization offered by Web 2.0 technologies, developing the tools embedded in NHS Choices but in ways that really do allow properly tailored information. Linked to tailoring and personalization, one issue that emerged strongly in Net.Weight was the need for local information.

\section{The Importance of "the Local"}

The Net.Weight study showed that information about local services that could support weight management activities was valued and needed. However, at the same time, local websites were rarely accessed or used in support of weight management, largely because they were not known about. Key among information providers in Brighton \& Hove at the time were the NHS primary care trust (PCT) and the city council, who were jointly responsible for the city's commendable Active for Life initiatives (Brighton \& Hove City Council \& NHS Brighton and Hove, 2006). A good deal of information relevant for weight management did-and does-exist, but much of it proved difficult for the research participants to find using commonsense search terms and a search engine. Furthermore, at the time of the research, no single portal or "one-stop shop" for "healthy living" information existed in the city. The situation changed with the launch in July 2009 of a pilot scheme, Information Prescriptions Brighton \& Hove (Brighton \& Hove City Council \& NHS Brighton and Hove, n.d.). This has provided the opportunity for a one-stop shop for healthy living information, although future funding for this initiative is uncertain. 
Some clear recommendations for local information providers thus arose from the study:

- Investigate ways to increase awareness of local websites that contain information relevant for weight management and healthy living

- Provide and develop localized versions of large national websites, such as NHS Choices

- Give further consideration to the provision of a "one-stop shop" for healthy living information in the city

- Undertake further design and development work on local health information websites to make them more accessible and useful to those engaged in weight management activities in the city

- Evaluate the longer-term use and impacts of such initiatives.

- Investigate the mismatch of keywords used by designers and users of health information websites to support improved website design and development

Overall, the research suggested that there is considerable potential for Web 2.0 technologies to increase the local "feel of websites by enabling generic information to be applied in local contexts. One example offered was that users could enter their postcode and receive personalized information about walks in their neighbourhood.

\section{"Blended" Support}

As noted above, Net.Weight demonstrated that while information is an important component of weight management, human intervention is also needed, particularly in the form of peer support. The study found that participation in the Net.Weight workshops, together with the ICT skills acquired, contributed to ongoing, mutual communication and support among participants: "Well the thing that struck me most was I'm not the only one. It was so nice hearing other people saying the same things as I thought" [Interviewee]. The social networks that developed alongside the workshops provided an important source of support and motivation for those engaged in weight management. They also enhanced learning through the sharing of information, skills, and experiences with peers. In the second workshop in the series, called Sharing and Community, the participants were given the opportunity to explore online social networking. They were shown how to use an online discussion forum and set up a blog, after which they contributed their own content and watched it evolve. The virtual networks took off through the sharing of recipes and the continuation of "real world" conversations about cooking: "I love the roasted asparagus suggestion! I've had it before with cheese but the garlic and lemon juice mean it wouldn't need parmesan" [blog post on Net. Weight.Community]. Throughout this second workshop, participants made suggestions for improvements that could be made to Net.Weight. 
Community. These included some navigation changes, adding forums for sharing jokes, ways to share information about local walks with links to maps, places to source reasonably-priced clothes for larger sizes, and where to access exercise opportunities for people with specific disabilities. Discussions about how these changes would be made had the effect of both making visible the often invisible work behind the Web, and of demonstrating how participants were becoming co-designers, as well as users, of Net.Weight.Community.

Some participants could see considerable potential for social networking: "Even not weight related, [the Internet's] quite good anyway, because sometimes people when they're overweight can be, get quite insular as well and using the Internet can open new avenues to all sorts of things ... chatting to people online and things" [Interviewee]. However, while some participants enjoyed online social networking activities and gained much from them, there was a strong sense that they did not replace face-to-face interaction: "this sort of thing [online social networking] could never take the place of a face to face meeting" [workshop participant]. "For me anything to do with health or weight probably there does need to be a physical group and then supported by the internet" [Interviewee]. The study also found that the impetus for maintaining blogs or online discussions trailed off after the workshops and concluded that while there is potential for ICTs, particularly social networking and Web 2.0 technologies, such as blogs to contribute to mutual communication and support among participants, this can only work if those contributing receive regular feedback. A "critical mass" of contributors is also required. This suggests that there is a need for some sort of human intervention or stimulation, such as a face-to-face meeting and/or active facilitation, for momentum to be sustained. It further suggests that the way forward is a "blended" approach to weight management support, combining online and offline components. Thus the study made the following recommendations for local service providers:

- Explore the potential for using the Net.Weight Community model to strengthen social networks

- Develop strategies for supporting weight management/healthy living that combine on- and off-line components, that is, a "blended" approach

- Encourage users of such "blended" approaches to use blogs and other diary-type tools to record practices, share ideas, experiences and information, and help motivate others

However, this "blended" approach, familiar in education, does not appear to be embedded in NHS culture. Liberating the NHS (Department of Health, 2010b) stresses the importance of technology in offering more 
efficient and effective ways of delivering health and in developing a usercentered service, while at times downplaying the importance of the human mediator: "Modern technology plays an ever-increasing part in our everyday lives. From online banking to searching the Internet, we have come to expect more convenient services, supported by quick and easy access to information. Yet many parts of our health and care systems still rely on face-to-face contact ..." (Department of Health, 2010b, p. 6). Previous policy agendas have also tended to link the implementation of ICTs with the development of a patient-centred health service, without the mechanisms by which this link works being fully explicated. For example, the development of health information services offered via NHS Direct and digital interactive television (DiTV) in the late 1990s was said to widen access to information in ways that support the development of self-care and patient empowerment (Nicholas, Huntington, \& Williams, 2003; Nicholas, Huntington, Williams, \& Jordan, 2002). The Patient Information Forum $(\mathrm{PiF})$, in its response to the 2010 government consultation, points out a flaw in the assumption that online activity, on its own, is effective or equitable: "The information available on NHS Choices/NHS Direct is valuable but rarely integrated into care and [is] left to those patients with the skills and knowledge to access such sources independently" (Patient Information Forum, 2011, p. 5).

Net.Weight concluded that while online tools have much to offer in terms of personalizing information and facilitating peer group support, they are not a replacement for integrated care and face-to-face contact. Net.Weight further emphasizes the need to build peer group support into the information provision equation and for online and "real world" activities to support and strengthen each other.

\section{Conclusion}

The Net.Weight study has contributed to an understanding of health and information literacy within the context of people's everyday information practices. The results suggest that the typical information literacy staged model needs to be developed and expanded in ways that take account of: the variety of information sources and types that people use, find useful, and need; the need for human intervention to support and supplement information; the empowering effects of peer support and participation; and the need to view people as both providers and users of information. Within the context of consumer health, a broader and more social approach to information literacy is needed to ensure a better "fit" between the provision and use of information. At policy and institutional levels, the study has shown that using ICTs can augment information provision and support activities but that a "blended" approach is necessary, where online and "real world" communication work in tandem. 


\section{Notes}

The Net.Weight study is a Department of Health-funded study formally entitled "Supporting the Self Management of Obesity: The Role of Information and Communication Technologies (ICTs)." The final report is available online (Net.Weight, 2009). This is an independent report commissioned and funded by the Policy Research Programme in the Department of Health in England. The views expressed there, as in this article, are not necessarily those of the Department.

\section{REFERENCES}

Adams, S., de Bont, A., \& Berg, M. (2006). Looking for answers, constructing reliability: An exploration into how Dutch patients check Web-based medical information. International Journal of Medical Informatics, 75(1), 66-72.

Brighton \& Hove City Council, \& NHS Brighton and Hove. (2006). Active for Life: More people, more active, more often. Retrieved December 1, 2011, from http://www.active forlife.org.uk

Brighton \& Hove City Council, \& NHS Brighton and Hove. (n.d.). Information prescriptions. Retrieved December 1, 2011, from http://www.ipbh.org.uk

Childs, S. (2004). Developing health website quality assessment guidelines for the voluntary sector: Outcomes from the Judge Project. Health Information and Libraries Journal, 21(Suppl 2), 1426 .

CILIP. (2007). Information literacy: A definition of information literacy. Retrieved December 1, 2011, from http://www.cilip.org.uk/policyadvocacy/learning/informationliteracy/ definition/definition.htm

Coulter, A., \& Ellins, J. (2006). Patient-focused interventions: A review of the evidence. London: Health Foundation.

Craig, E. (2009). Better informed for better health and better care: An information literacy framework to support health care in Scotland. Health Information and Libraries Journal, 26(1), 77-80.

Cullen, R. (2005). Empowering patients through health literacy training. Library Review, 54(4), 231-244

Department of Health. (2005). Public attitudes to self care: Baseline survey. London: Department of Health.

Department of Health. (2008). NHS choices. Retrieved December 1, 2011, from http:// www.nhs.uk

Department of Health. (2009). Information prescriptions. Retrieved December 1, 2011, from http://www.informationprescription.info/

Department of Health. (2010a). The NHS Constitution. Retrieved December 1, 2011, from http://www.nhs.uk/choiceintheNHS/Rightsandpledges/NHSConstitution/Documents/ nhs-constitution-interactive-version-march-2010.pdf

Department of Health. (2010b). Liberating the NHS: An information revolution. Retrieved December 1, 2011, from http://www.dh.gov.uk/prod_consum_dh/groups/dh_digitalassets/@ $\mathrm{dh} / @$ en/documents/digitalasset/dh_120598.pdf

Department of Health. (2010c). Equity and excellence: Liberating the NHS. Retrieved December 1, 2011, from http://www.dh.gov.uk/en/Publicationsandstatistics/Publications/Publi cationsPolicyAndGuidance/DH_117353

Ellins, J., \& Coulter, A. (2005). How engaged are people in their health care? London: Health Foundation.

Henwood, F., Marshall, A., Carlin, L., Guy, E. S., \& Smith, H. (2009). Final report on the Net. Weight Project. Retrieved December 1, 2011, from http://research.cmis.brighton.ac.uk/ netweight/report

Huntington, P., Nicholas, D., Williams, P., \& Gunter, B. (2002). Characterising the health information consumer: An examination of digital television users. Libri, 52(1), 16-27.

Johnston, B., \& Webber, S. (2006). As we may think: Information literacy as a discipline for the information age. Research Strategies, 20(3), 108-121.

Kars, M., Baker, L. M., \& Wilson, F. M. (2008). The Medical Library Association guide to health literacy. New York: Neal-Schuman.

Kuhlthau, C. C. (2008). From information to meaning: Confronting challenges of the twentyfirst century. Libri, 58(2), 66-73. 
Marshall, A., Henwood, F., Carlin, L., Guy, E. S., \& Smith, H. (2010). In the balance: report of a research study exploring information for weight management. Libri, 60(2), 142-152.

Marshall, L. A., \& Williams, D. (2006). Health information: does quality count for the consumer?: How consumers evaluate the quality of health information across a wide variety of media. Journal of Librarianship and Information Science, 38(3), 141-156.

McKenzie, P. J. (2003). A model of information practices in accounts of everyday-life information seeking. Journal of Documentation, 59(1), 19-40.

National Voices. (2010). National Voices' response to the consultations: "Liberating the NHS: an information revolution" and "Liberating the NHS: Greater choice and control." London: National Voices. Retrieved December 1, 2011, from http://www.nationalvoices.org.uk

Net.Weight. (2009, November). Final report. Retrieved December 1, 2011, from http:// research.cmis.brighton.ac.uk/netweight/report

Net.Weight. (2008). Net.Weight Community. Retrieved March 1, 2011, from http://research. cmis.brighton.ac.uk/netweight.community/

NHS Direct. (1999). NHS Direct. Retrieved December 1, 2011, from http://www.nhsdirect .nhs.uk/

NHS Executive. (1998). Information for health: An information strategy for the modern NHS 19982005. London: Department of Health.

Nicholas, D., Huntington, P., \& Williams, P. (2003). Perceptions of the authority of health information: Case study digital interactive television and the Internet. Health Informatics Journal, 20, 215-224.

Nicholas, D., Huntington, P., Williams, P., \& Jordan, M. (2002). NHS Direct online: Its users and their concerns. Journal of Information Science, 28(4), 305-319.

Norman, C. D., \& Skinner, H. A. (2006). eHealth literacy: Essential skills for consumer health in a networked world. Journal of Medical Internet Research, 8(2), e9.

Nutbeam, D. (2008). The evolving concept of health literacy. Social Science $\mathcal{E}^{2}$ Medicine, 67, 2072-2078.

Patient Information Forum. (2011). Patient Information Forum (PiF) response to the consultations: "Liberating the NHS: An information revolution" and "Liberating the NHS: Greater choice and control."London: Patient Information Forum.

SCONUL. (1999, October). Briefing paper: Information skills in higher education. Retrieved December 1, 2011, from http://www.sconul.ac.uk/groups/information_literacy/papers/ Seven_pillars2.pdf

Shepperd, S., Charnock, D., \& Gann, R. (1999). Helping patients access high quality health information. BMJ, 319, 764-766.

Smith, S., \& Duman, M. (2009). The state of consumer health information: An overview. Health Information and Libraries Journal, 26(4), 260-278.

Webber, S., \& Johnston, B. (2000). Conceptions of information literacy: New perspectives and implications. Journal of Information Science, 26(6), 381-397.

World Health Organization. (1998). Health promotion glossary. Geneva: World Health Organization.

Audrey Marshall is a senior lecturer in the School of Computing, Engineering and Mathematics, University of Brighton, UK. She is course leader for the MA in Information Studies. She has worked in a range of library and information sectors, including public libraries and health information services and is an active member of CILIP, the professional body for library and information specialists in the UK. Her research interests revolve around the uses of information and ICTs for health, focusing particularly on information literacy in a public health context. She has published articles in Library and Information Research, the Journal of Information Literacy and Libri.

Flis Henwood is professor of Social Informatics in the School of Applied Social Science, University of Brighton, UK. Her most recent research engages with e-health discourse and the policies and practices of e-health technology implementations in a range of organizational and social contexts. Her focus is on questions of user engagement with e-health technologies and on factors affecting the use and non-use of these technologies. Professor Henwood's research is interdisciplinary and has been 
published in social science (Sociology of Health and Illness, Critical SocialPolicy) as well as information and informatics journals (Journal of Information Literacy, Health Information and Libraries Journal, Reference and User Services Quarterly, Health Informatics Journal). Relevant publications include a Special "e-health" issue of the journal Information, Communication and Society (with Ellen Balka in 2004) and the book Gender, Health and Information Technology in Context (co-edited with Ellen Balka and Eileen Green in 2009).

Elizabeth Guy is a senior lecturer in Web design and development in the School of Computing, Engineering and Mathematics at the University of Brighton, UK. Her research background is computer-supported cooperative work and design ethnography, focusing on how computer artifacts mediate collaborative human activity and the implications for design. Most recently she has worked as a researcher on the Net.Weight project, looking at the potential of computer technologies to support weight management. 